\title{
Length of stay, hospitalization cost, and in-hospital mortality in US adult inpatients with immune thrombocytopenic purpura, 2006-2012
}

This article was published in the following Dove Press journal:

Vascular Health and Risk Management

20 January 2017

Number of times this article has been viewed

\author{
Ruopeng An' \\ Peizhong Peter Wang ${ }^{2}$ \\ 'Department of Kinesiology and \\ Community Health, College of Applied \\ Health Sciences, University of Illinois \\ at Urbana-Champaign, Champaign, IL, \\ USA; ${ }^{2}$ Faculty of Medicine, Memorial \\ University of Newfoundland, St. John's, \\ NL, Canada
}

Purpose: In this study, we examined the length of stay, hospitalization cost, and risk of inhospital mortality among US adult inpatients with immune thrombocytopenic purpura (ITP). Methods: We analyzed nationally representative data obtained from Nationwide/National Inpatient Sample database of discharges from 2006 to 2012.

Results: In the US, there were an estimated 296,870 (95\% confidence interval [CI]: 284,831-308,909) patient discharges recorded for ITP from 2006 to 2012, during which ITPrelated hospitalizations had increased steadily by nearly $30 \%$. The average length of stay for an ITP-related hospitalization was found to be 6.02 days (95\% CI: 5.93-6.10), which is $28 \%$ higher than that of the overall US discharge population (4.70 days, 95\% CI: 4.66-4.74). The average cost of ITP-related hospitalizations was found to be US\$16,594 (95\% CI: US\$16,257US\$16,931), which is $48 \%$ higher than that of the overall US discharge population (US\$11,200; 95\% CI: US\$11,033-US\$11,368). Gender- and age-adjusted mortality risk in inpatients with ITP was $22 \%$ (95\% CI: 19\%-24\%) higher than that of the overall US discharge population. Across diagnosis related groups, length of stay for ITP-related hospitalizations was longest for septicemia (7.97 days, 95\% CI: 7.55-8.39) and splenectomy (7.40 days, 95\% CI: 6.94-7.86). Splenectomy (US\$25,262; 95\% CI: US\$24,044-US\$26,481) and septicemia (US\$18,430; 95\% CI: US\$17,353-US\$19,507) were associated with the highest cost of hospitalization. The prevalence of mortality in ITP-related hospitalizations was highest for septicemia $(11.11 \%, 95 \%$ CI: 9.60\%-12.63\%) and intracranial hemorrhage (9.71\%, 95\% CI: 7.65\%-11.77\%).

Conclusion: Inpatients with ITP had longer hospital stay, bore higher costs, and faced greater risk of mortality than the overall US discharge population.

Keywords: hospitalization, inpatient, cost, mortality, length of stay, immune thrombocytopenic purpura, national inpatient sample

\section{Introduction}

Immune thrombocytopenic purpura (ITP) is an autoimmune disorder characterized by low platelet count caused due to increased platelet destruction and suboptimal platelet production. ${ }^{1,2}$ It is a rare disorder with an annual incidence of approximately 1.6 cases per 100,000 persons among adult population. ${ }^{2}$ ITP in adults is usually chronic, and the goal of the treatment is to raise the platelet count to a hemostatically safe range. ${ }^{3,4}$ Undertreated ITP can result in life-threatening events such as intracranial hemorrhage and septicemia. ${ }^{5,6}$ Complications of ITP often require intensive health care that mandates hospitalization. ${ }^{7}$ Clinical outcomes and financial impact of ITP-related
Correspondence: Ruopeng An Department of Kinesiology and Community Health, College of Applied Health Sciences, University of Illinois at Urbana-Champaign, 1206 South 4th Street, Champaign, IL 61820, USA

Tel +I 2172440966

Fax +I 2173332766

Email ran5@illinois.edu 
hospitalizations are critical in measuring the disease burden of ITP keeping health care providers, payers, and other stakeholders informed. However, national data on ITP-related hospitalizations remain scarce. To our knowledge, Danese et al's ${ }^{8}$ study is the only one that examined hospitalization outcomes associated with ITP from 2003 to $2006 .{ }^{8}$ They used the diagnosis code for primary thrombocytopenia (ICD-9 code: 287.3 ) to identify ITP-related hospitalizations between January 1, 2003, and September 30, 2005, as the ITP-specific diagnosis code (ICD-9 code: 287.31) was unavailable prior to October $1,2005 .^{8}$

In this study, we used 7-year nationally representative inpatient data from 2006 to 2012 and examined the length of stay, hospitalization cost, and in-hospital mortality associated with ITP in US adult population. Patients with $\geq 18$ years at the time of admission were included. We used the ITP-specific diagnosis code (ICD-9 code: 287.31 ) to consistently identify ITP-related hospitalizations throughout the study period. We tracked the national trend for ITP-related hospitalizations over time, classified it by diagnosis-related group (DRG), and compared its outcome with the overall US discharge population across different age cohorts.

\section{Materials and methods}

We obtained hospitalization data from National (nationwide) Inpatient Sample (NIS) database from 2006 to 2012. Sponsored by the Agency of Healthcare Research and Quality, the NIS is a database of hospital inpatient stays derived from billing data submitted by hospitals to statewide data organizations across the US. These inpatient data include clinical and resource use information typically available from discharge abstracts. The NIS includes patients of all payer types, including those covered by Medicare, Medicaid, or private insurance, as well as the uninsured. The NIS sampling frame currently covers $97 \%$ of the US population and nearly the entire universe of discharges. The uniquely large sample size enables the NIS to produce national estimates on rare conditions, uncommon treatments, and special populations. The NIS sampling design was modified in 2012 to improve national estimate precisions. We used the revised sampling weights for the NIS 2011 and prior data to make estimates comparable to the new sampling design beginning with 2012 data. Detailed information on the NIS can be found on its website (https://www.hcup-us.ahrq.gov/databases.jsp).

The NIS tracks discharges rather than unique patients; therefore, the same patient with multiple hospitalizations in a year is potentially sampled more than once. Therefore, in this study, we chose discharge data as the unit of analysis.
A discharge was identified as an ITP-related hospitalization if any of up to 25 (or 15 for prior-2009 NIS data) principal/ secondary diagnosis code fields include ICD-9 code 287.31 for patients with $\geq 18$ years of age at the time of admission. Following Danese et al, we further classified ITP-related hospitalizations into seven mutually exclusive discharge groups using the primary reason for hospitalization as denoted by the DRG. ${ }^{8}$ Reasons for discharges were first divided into two categories: 1) splenectomy (ICD-9 procedure code: 415 ) and (2) other reasons. The categories for other reasons were divided into six discharge subgroups: coagulation disorder (DRG version 24 code: 397), gastrointestinal hemorrhage (DRG version 24 code: 174 and 175), intracranial hemorrhage (version 24 code: DRG 14 and 528), epistaxis (DRG version 24 code: 66 ), septicemia (DRG version 24 code: 575 and 576), and all others.

The discharge outcomes included length of stay, hospitalization cost, and in-hospital mortality. Hospitalization cost was obtained by deflating the total charges using the NIS-provided annual hospital-specific cost-to-charge ratios and then inflated to the 2012 US dollars using the medical care Consumer Price Index of the US Bureau of Labor Statistics. ${ }^{9}$ Standardized mortality ratios (SMRs) were calculated from the estimated gender- and age-specific in-hospital deaths associated with ITP, using the entire 2006-2012 NIS sample (excluding inpatients with ITP) as the reference population.

Individual demographics included gender (male and female), age group (18-24, 25-34, 35-44, 45-54, 55-64, $65-74,75-84$, and $\geq 85$ years), and race/ethnicity (non-Hispanic White, non-Hispanic African American, non-Hispanic Asian or Pacific Islander, non-Hispanic Native American, non-Hispanic other race or multi-race, and Hispanic).

The NIS sampling design was incorporated in all statistical analyses to produce population-level estimates. Statistical analyses were performed in Stata version 14.2 SE (StataCorp LP, College Station, TX, USA).

In this study, we involved secondary-data analysis of deidentified, publicly available data that was deemed exempt from human subjects review by the University of Illinois at Urgana-Champaign Institutional Review Board.

\section{Results}

Table 1 reports individual demographics and length of stay, hospitalization cost, and in-hospital mortality for ITP-related hospitalizations. Over the 7-year period between 2006 and 2012, the NIS documented a total of 62,299 discharges for patients with ITP, representing an estimated 296,870 (95\% 
Table I Individual demographics and length of stay, hospitalization cost, and in-hospital mortality in immune thrombocytopenic purpura (ITP)-related hospitalizations, National Inpatient Sample (NIS) 2006-2012

\begin{tabular}{|c|c|}
\hline Variables & Statistic \\
\hline Unweighted discharges & 62,299 \\
\hline Estimated national discharges & $296,870(284,83 \mathrm{I}-308,909)$ \\
\hline \multicolumn{2}{|l|}{ Discharge outcome } \\
\hline Hospital length of stay (day) & $6.02(5.93-6.10)$ \\
\hline Hospitalization-related cost (2012 US\$) & $16,594(16,257-16,931)$ \\
\hline In-hospital mortality (\%) & $3.08(2.93-3.23)$ \\
\hline Standardized mortality ratio & $1.22(1.19-1.24)$ \\
\hline \multicolumn{2}{|l|}{ Sex (\%) } \\
\hline Male & $40.87(40.27-4 \mid .47)$ \\
\hline Female & $59.13(58.53-59.73)$ \\
\hline $\begin{array}{l}\text { Age group in years at the time of } \\
\text { admission (\%) }\end{array}$ & $16,594(16,257-16,931)$ \\
\hline $18-24$ & $5.56(5.3 \mathrm{I}-5.82)$ \\
\hline $25-34$ & $10.39(10.00-10.78)$ \\
\hline $35-44$ & $8.36(8.05-8.67)$ \\
\hline $45-54$ & II.05 (I0.69-|I.4I) \\
\hline $55-64$ & $14.74(14.35-15.13)$ \\
\hline $65-74$ & $17.55(17.14-17.96)$ \\
\hline $75-84$ & $20.75(20.21-21.30)$ \\
\hline$\geq 85$ years & 11.59 (II.19-11.99) \\
\hline \multicolumn{2}{|l|}{ Race/ethnicity (\%) } \\
\hline White, non-Hispanic & 73.31 (72.02-74.60) \\
\hline African American, non-Hispanic & $10.61(9.95-11.28)$ \\
\hline Asian or Pacific Islander, non-Hispanic & $2.46(2.16-2.76)$ \\
\hline Native American, non-Hispanic & $0.47(0.36-0.59)$ \\
\hline Other race/multi-race, non-Hispanic & $2.97(2.58-3.36)$ \\
\hline Hispanic & $10.18(9.23-11.13)$ \\
\hline
\end{tabular}

Notes: Descriptive statistics accounted for the NIS sampling design; $95 \%$ confidence intervals are presented in parentheses. confidence interval $[\mathrm{CI}]=284,831-308,909)$ patient discharges nationally for ITP. The average length of stay for an ITP-related hospitalization was found to be 6.02 days $(95 \%$ $\mathrm{CI}=5.93-6.10)$, which is $28 \%$ higher than that of the overall US discharge population ( 4.70 days, $95 \% \mathrm{CI}=4.66-4.74$ ). The average cost of ITP-related hospitalizations was found to be US\$16,594 (95\% CI = US\$16,257-US\$16,931), which is $48 \%$ higher than that of the overall US discharge population (US\$11,200, 95\% CI = US\$11,033-US\$11,368). In-hospital mortality prevalence for ITP was found to be $3.08 \%$ (95\% $\mathrm{CI}=2.93 \%-3.23 \%)$, in comparison to $2.22 \%(95 \% \mathrm{CI}=$ $2.19 \%-2.25 \%$ ) for the overall US discharge population. Women accounted for nearly $60 \%$ of all ITP-related hospitalizations. Over three-quarters of ITP-related hospitalizations occurred in middle-aged and older adults ( $\geq 45$ years) and nearly half in older adults ( $\geq 65$ years). Non-Hispanic whites occupied nearly three-quarters of ITP-related hospitalizations, whereas non-Hispanic African Americans and Hispanic both accounted for slightly over $10 \%$.

Table 2 reports length of stay, hospitalization cost, and in-hospital mortality in ITP-related hospitalizations by DRG. Coagulation disorder was found to be the most prevalent reason for ITP-related hospitalizations (in addition to all other reasons that were unclassified by DRG), accounting for $67,721(22.81 \%)$ discharges nationwide, followed by splenectomy (13,055 discharges or $4.40 \%)$, septicemia $(8,075$ discharges or $2.72 \%)$, gastrointestinal hemorrhage $(5,286$ discharges or $1.78 \%)$, intracranial hemorrhage $(3,790$ or $1.28 \%)$, and epistaxis (249 discharges

Table 2 Length of stay, hospitalization cost, and in-hospital mortality in immune thrombocytopenic purpura (ITP)-related hospitalizations by diagnosis-related group (DRG), National Inpatient Sample (NIS) 2006-20I2

\begin{tabular}{|c|c|c|c|c|c|c|c|c|}
\hline $\begin{array}{l}\text { Discharge } \\
\text { outcome }\end{array}$ & All & Splenectomy & $\begin{array}{l}\text { Coagulation } \\
\text { disorder }\end{array}$ & $\begin{array}{l}\text { Gastrointestinal } \\
\text { hemorrhage }\end{array}$ & $\begin{array}{l}\text { Intracranial } \\
\text { hemorrhage }\end{array}$ & Septicemia & Epistaxis & Others \\
\hline $\begin{array}{l}\text { Unweighted } \\
\text { discharges }\end{array}$ & 62,299 & 2,742 & 14,194 & 1,099 & 796 & 1,710 & 52 & $4 I, 706$ \\
\hline $\begin{array}{l}\text { Estimated } \\
\text { national } \\
\text { discharges }\end{array}$ & $\begin{array}{l}296,870 \\
(284,831- \\
308,909)\end{array}$ & $\begin{array}{l}13,055 \\
(12,228-13,883)\end{array}$ & $\begin{array}{l}67,721 \\
(64,632- \\
70,809)\end{array}$ & $\begin{array}{l}5,286 \\
(4,897-5,676)\end{array}$ & $\begin{array}{l}3,790 \\
(3,476-4,106)\end{array}$ & $\begin{array}{l}8,075 \\
(7,533- \\
8,618)\end{array}$ & $\begin{array}{l}249 \\
(|8|-3 \mid 7)\end{array}$ & $\begin{array}{l}198,692 \\
(190,370- \\
207,013)\end{array}$ \\
\hline $\begin{array}{l}\text { Length of } \\
\text { stay (days) }\end{array}$ & $\begin{array}{l}6.02 \\
(5.93-6.10)\end{array}$ & $\begin{array}{l}7.40 \\
(6.94-7.86)\end{array}$ & $\begin{array}{l}4.70 \\
(4.61-4.80)\end{array}$ & $\begin{array}{l}5.19 \\
(4.92-5.45)\end{array}$ & $\begin{array}{l}6.43 \\
(5.94-6.92)\end{array}$ & $\begin{array}{l}7.97 \\
(7.55-8.39)\end{array}$ & $\begin{array}{l}2.84 \\
(2.27-3.4 I)\end{array}$ & $\begin{array}{l}6.3 \mathrm{I} \\
(6.2 \mathrm{I}-6.4 \mathrm{I})\end{array}$ \\
\hline $\begin{array}{l}\text { Hospitalization } \\
\text { cost }(2012 \\
\text { US } \$)\end{array}$ & $\begin{array}{l}16,594 \\
(16,257- \\
16,931)\end{array}$ & $\begin{array}{l}25,262 \\
(24,044-26,48 I)\end{array}$ & $\begin{array}{l}16,224 \\
(15,738- \\
16,711)\end{array}$ & $\begin{array}{l}13,964 \\
(|2,539-| 5,389)\end{array}$ & $\begin{array}{l}17,280 \\
(15,663- \\
18,897)\end{array}$ & $\begin{array}{l}18,430 \\
(17,353- \\
19,507)\end{array}$ & $\begin{array}{l}6,654 \\
(4,855- \\
8,453)\end{array}$ & $\begin{array}{l}16,14 \mid \\
(15,775- \\
16,507)\end{array}$ \\
\hline $\begin{array}{l}\text { In-hospital } \\
\text { mortality (\%) }\end{array}$ & $\begin{array}{l}3.08 \\
(2.93-3.23)\end{array}$ & $\begin{array}{l}2.19 \\
(1.64-2.75)\end{array}$ & $\begin{array}{l}1.45 \\
(1.24-1.65)\end{array}$ & $\begin{array}{l}3.96 \\
(2.80-5.13)\end{array}$ & $\begin{array}{l}9.71 \\
(7.65-11.77)\end{array}$ & $\begin{array}{l}11.11 \\
(9.60-12.63)\end{array}$ & 0 & $\begin{array}{l}3.22 \\
(3.04-3.40)\end{array}$ \\
\hline $\begin{array}{l}\text { Standardized } \\
\text { mortality ratio }\end{array}$ & $\begin{array}{l}1.22 \\
(1.19-1.24)\end{array}$ & $\begin{array}{l}1.15 \\
(1.02-1.29)\end{array}$ & $\begin{array}{l}0.66 \\
(0.62-0.70)\end{array}$ & $\begin{array}{l}1.15 \\
(1.00-1.32)\end{array}$ & $\begin{array}{l}2.90 \\
(2.6 \mathrm{I}-3.2 \mathrm{I})\end{array}$ & $\begin{array}{l}3.39 \\
(3.18-3.62)\end{array}$ & 0 & $\begin{array}{l}1.23 \\
(1.20-1.26)\end{array}$ \\
\hline
\end{tabular}

Notes: Descriptive statistics accounted for the NIS sampling design; $95 \%$ confidence intervals are presented in parentheses. 
or $0.08 \%)$. Length of stay for ITP-related hospitalizations was found to be the longest for septicemia (7.97 days, 95\% CI $=7.55-8.39)$ and splenectomy (7.40 days, $95 \%$ $\mathrm{CI}=6.94-7.86)$ and shortest for epistaxis (2.84 days, $95 \%$ $\mathrm{CI}=2.27-3.41)$. Splenectomy $(\mathrm{US} \$ 25,262,95 \% \mathrm{CI}=$ US\$24,044-US\$26,481) and septicemia (US\$18,430, 95\% $\mathrm{CI}=\mathrm{US} \$ 17,353-\mathrm{US} \$ 19,507)$ were associated with the highest hospitalization cost, whereas epistaxis (US\$6,654, 95\% $\mathrm{CI}=\mathrm{US} \$ 4,855-\mathrm{US} \$ 8,453)$ was associated with the lowest cost. The prevalence of mortality in ITP-related hospitalizations was found to be the highest for septicemia $(11.11 \%$, 95\% CI $=9.60 \%-12.63 \%)$ and intracranial hemorrhage $(9.71 \%, 95 \% \mathrm{CI}=7.65 \%-11.77 \%)$, whereas it was lowest for coagulation disorders $(1.45 \%, 95 \% \mathrm{CI}=1.24 \%-1.65 \%)$ and epistaxis (no death reported in 2006-2012 NIS).

Figure 1 shows the estimated national trend for ITP-related hospitalization frequencies from 2006 to 2012. Over the 7 year period, ITP-related hospitalizations in the US increased by nearly $30 \%$ from $35,266(95 \% \mathrm{CI}=32,870-37,662)$ in 2006 to 45,520 (95\% CI = 43,982-47,058) in 2012.

Figure 2 shows the estimated national trend for ITPrelated hospitalization frequencies by age group. During 2006-2012, the total ITP-related hospitalizations in the US increased from approximately $16,519(95 \%$ $\mathrm{CI}=15,573-17,465)$ in the age group of $18-24$ years to $61,614(95 \% \mathrm{CI}=58,552-64,676)$ in the age group of $75-84$ years, which declined to $34,400(95 \% \mathrm{CI}=32,665-36,135)$ in the age group of $\geq 85$ years.

Figure 3 shows the estimated mortality prevalence in ITP-related hospitalizations by age group. In-hospital mortality rate associated with ITP increased monotonically with age from $0.29 \%(95 \% \mathrm{CI}=0.11 \%-0.46 \%)$ in the age group of $18-24$ years to $5.64 \%(95 \% \mathrm{CI}=5.10 \%-6.18 \%)$ in the age group of $\geq 85$ years. In-hospital mortality rate was

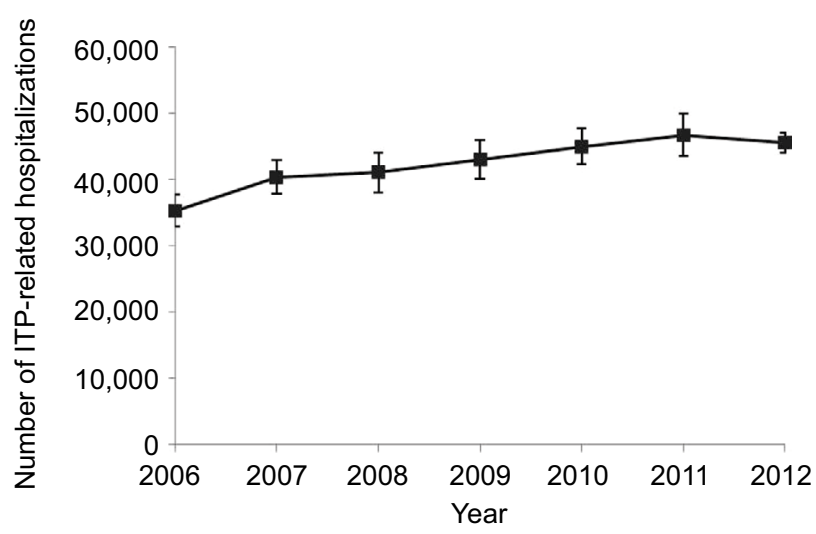

Figure I Estimated annual immune thrombocytopenic purpura (ITP)-related hospitalization frequencies in the US, National Inpatient Sample (NIS) 2006-20I2.

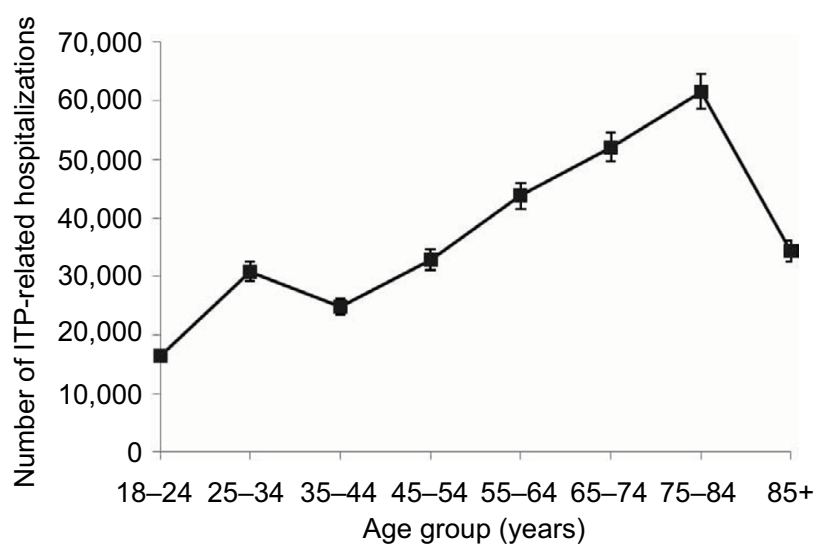

Figure 2 Estimated immune thrombocytopenic purpura (ITP)-related hospitalization frequencies in the US by age groups, National Inpatient Sample (NIS) 2006-20I2.

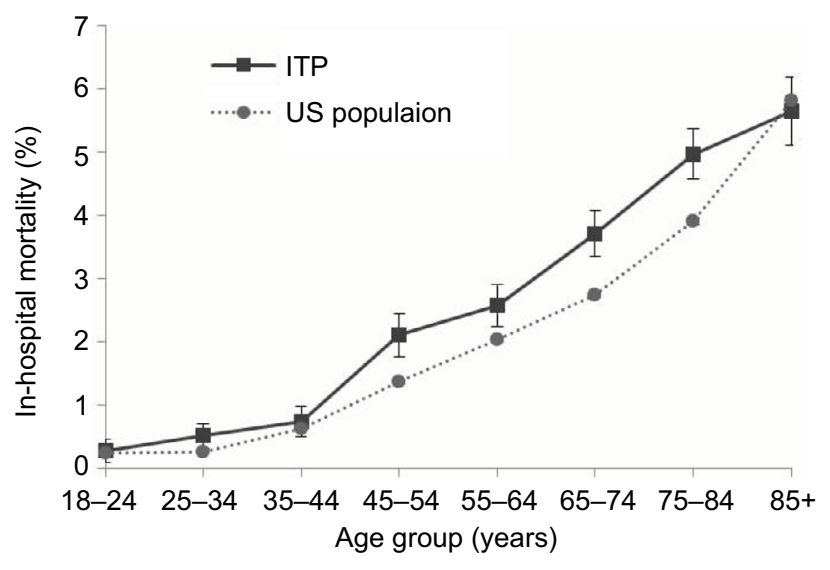

Figure 3 Age-specific in-hospital mortality prevalence in immune thrombocytopenic purpura (ITP)-related hospitalizations, National Inpatient Sample (NIS) 2006-20I 2.

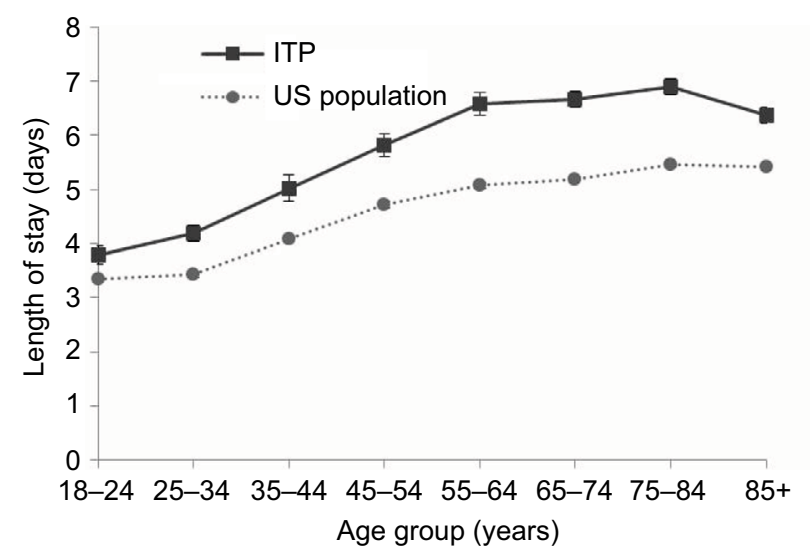

Figure 4 Age-specific length of stay for immune thrombocytopenic purpura (ITP)related hospitalizations, National Inpatient Sample (NIS) 2006-20I2.

noticeably higher in patients with ITP than the overall US discharge population in the middle-age and older adults aged 45-84 years, whereas this difference was not statistically significant for those in the age group of $\geq 85$ years.

Figure 4 shows the estimated length of stay for ITP-related hospitalizations by age group. Length of stay in patients with 
ITP increased monotonically with age from 3.79 days ( $95 \%$ $\mathrm{CI}=3.62-3.95)$ in the age group of $18-24$ years to 6.89 days $(95 \% \mathrm{CI}=6.74-7.04)$ in the age group of $75-84$ years, which declined slightly to 6.36 days $(95 \% \mathrm{CI}=6.22-6.50)$ in the age group of $\geq 85$ years. Length of stay in patients with ITP was substantially longer than that of the overall US discharge population across all age groups.

Figure 5 shows the estimated cost of ITP-related hospitalizations by age group. Hospitalization cost associated with ITP largely formed an inverted U-shaped curve with respect to age, with cost increasing from US\$11,500 (95\% CI = US $\$ 10,955-$ US $\$ 12,044)$ in the age group of $25-34$ years to its peak of US\$19,470 (95\% CI = US\$18,768-US\$20,173) in the age group of 55-64 years, and then gradually declining to US $\$ 14,035(95 \% \mathrm{CI}=\mathrm{US} \$ 13,593-\mathrm{US} \$ 14,478)$ in the age group of $\geq 85$ years. The cost of hospitalization for patients with ITP was substantially higher than that of the overall US discharge population across all age groups.

Figure 6 shows the estimated cost per day of ITPrelated hospitalizations by age group. In the age group of

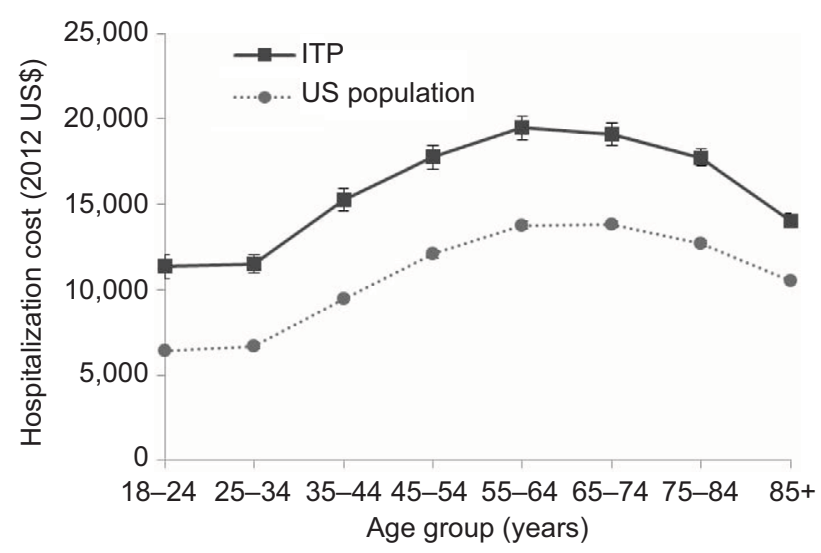

Figure 5 Age-specific hospitalization cost for immune thrombocytopenic purpura (ITP)-related hospitalizations, National Inpatient Sample (NIS) 2006-20I2.

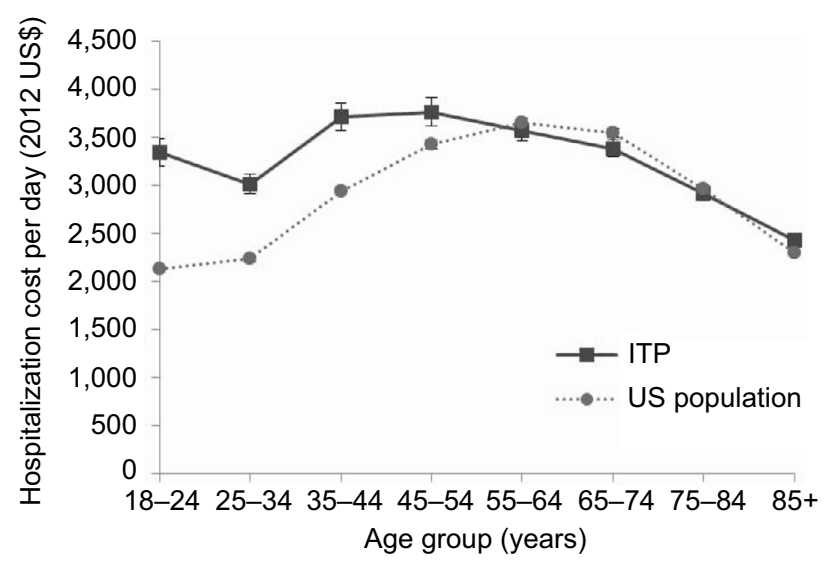

Figure 6 Age-specific hospitalization cost per day for immune thrombocytopenic purpura (ITP)-related hospitalizations, National Inpatient Sample (NIS) 2006-2012.
18-54 years, daily cost of ITP-related hospitalization was noticeably higher than that of the overall US discharge population, whereas in the age group $\geq 55$ years, their daily hospitalization costs remained similar.

The estimated SMR for ITP was $1.22(95 \% \mathrm{CI}=$ $1.19-1.24$ ), denoting a $22 \%$ higher in-hospital mortality risk in patients with ITP in comparison to the overall US discharge population. In-hospital mortality risk for ITP was comparable between genders. The estimated SMR for ITP was $1.21(95 \% \mathrm{CI}=1.17-1.24)$ among men and $1.23(95 \%$ $\mathrm{CI}=1.19-1.26)$ among women.

\section{Discussion}

In this study, we examined ITP-related hospitalization frequency, length of stay, hospitalization cost, and in-hospital mortality among US adults during 2006-2012. We used data from a nationally representative inpatient sample. There were an estimated 296,870 patient discharges nationally for ITP over the 7-year period, during which ITP-related hospitalizations increased steadily by nearly $30 \%$. The average length of stay for ITP-related hospitalizations was 6.02 days, with a cost totaling US\$16,594. Gender- and age-adjusted mortality risk for inpatients with ITP was $22 \%$ higher than that of the overall US discharge population. Coagulation disorder was the most prevalent reason for ITP-related hospitalizations. Length of stay for ITP-related hospitalizations was longest for septicemia and splenectomy. They also topped in hospitalization cost. The prevalence of mortality in ITP-related hospitalizations was highest for septicemia and intracranial hemorrhage compared to other reasons.

Findings from this study were fairly comparable to Danese et al's study, despite that the estimated in-hospital mortality prevalence (3.8\%) and SMR for ITP (1.5) in their study were to some extent higher. ${ }^{8}$ These discrepancies could be partially due to the differences in the inpatient population under study because in Danese et al's study (2009), they used diagnosis code for primary thrombocytopenia (ICD-9 code: 287.3) as a proxy for ITP due to the unavailability of ITP-specific diagnosis code (ICD-9 code: 287.31 ) prior to late $2005 .^{8}$

The steady increase in ITP-related hospitalizations during 2006-2012 is disconcerting. It is unclear what proportion of this increase reflected a true growth in ITP cases and what was "spurious," for example, providers' gradual adaption to the newly available ITP-specific diagnosis code or advancement in diagnosis of exclusion for ITP. Nevertheless, along with the nation's rapid transition into an aging society, ITP-related hospitalizations are likely to further increase, as older patients with ITP are at an elevated risk of medical complications that 
frequently demand intensive health care. ${ }^{10,11}$ This has been indicated in the study findings as the substantially longer length of stay and in-hospital mortality rate among older inpatients with ITP.

The persistent increase in ITP-related hospitalizations may also reflect poor disease management in the daily life of patients with ITP, which may result in an alarming decline in platelet count below hemostatically safe level and expose them to the risk of excessive bruising and bleeding. ${ }^{12,13}$ Closely monitoring platelet level and improving medication adherence can be essential to avert severe adverse events that lead to hospitalization in adult patients with chronic ITP. ${ }^{4,14,15}$

The inverted U-shaped hospitalization cost with respect to age was present for both inpatients with ITP and the overall US discharge population, ${ }^{16}$ which may reflect a dynamic interplay between disease manifestation and "treatability" during aging (e.g., many chronic conditions start to manifest in middle age, but aggressive treatments become less favorable as patients become rather old). Specific to ITP, a retrospective study of patients undergoing splenectomy for ITP found that patients with $\geq 65$ years of age but not their younger counterparts experienced negative effects on safety and efficacy outcomes of the procedure. ${ }^{17}$ In addition, the inverted U-shaped hospitalization cost with respect to age may also reflect the higher mortality rate among the elderly.

A few limitations of this study should be noted. The NIS tracks hospital discharges rather than patients; therefore, we were not able to track multiple discharges of the same patient over time. Patients admitted from the emergency department (ED) were included in the NIS, but visits limited to the ED were not. The NIS has a uniquely large sample size that enables relatively precise estimation on some rare diseases, such as ITP, but unlike national health survey or electronic medical record data, information regarding patients' socioeconomic and demographic characteristics, mental/physical health condition, and comorbidity or disease history are lacking in the NIS. The estimated hospitalization cost was limited to the "tangible" expenses incurred in hospital (e.g., physician/nurse's time, procedure cost, and devise/supply/medication use), whereas the "intangible" or opportunity cost incurred in patients (e.g., missed work days, travel cost, and caregiving) were not accounted for. Therefore, the total hospitalization cost by adding the patient's proportion could be larger than estimated. No finer breakdowns of hospitalization cost (e.g., by procedures) is available in the NIS. It is likely that patients undergoing laparoscopic splenectomy had shorter length of stay compared to their counterparts with open splenectomy, but such finer categorization for splenectomy is unavailable in the NIS.

\section{Conclusion}

Using data from a nationally representative inpatient sample, in this study, we examined hospitalization frequency, length of stay, cost, and mortality in US adult inpatients with ITP during 2006-2012. Over the 7-year period, the number of ITP-related discharges increased by $30 \%$ nationwide. Length of stay and hospitalization cost for patients with ITP were $28 \%$ and $48 \%$, respectively, which is higher than that of the overall US discharge population. Patients with ITP were at a $22 \%$ higher risk for in-hospital mortality compared to the overall US discharge population. As the nation rapidly transitions into an aging society, ITP-related hospitalizations could further increase, especially among vulnerable older patients with ITP. Closely monitoring their platelet level and improving their medication adherence can be critical to avert severe adverse events that lead to hospitalization in patients with chronic ITP.

\section{Acknowledgment}

This study was funded by the Amgen Foundation (grant \# C3083).

\section{Disclosure}

The authors report no conflicts of interest in this work.

\section{References}

1. Cines DB, Blanchette VS. Immune thrombocytopenic purpura. $N$ Engl J Med. 2002;346(13):995-1008.

2. Psaila B, Bussel JB. Immune thrombocytopenic purpura. Hematol Oncol Clin North Am. 2007;21(4):743-759.

3. Cines DB, McMillan R. Management of adult idiopathic thrombocytopenic purpura. Annu Rev Med. 2005;56:425-442.

4. British Committee for Standards in Hematology General Hematology Task Force. Guidelines for the investigation and management of idiopathic thrombocytopenic purpura in adults, children and in pregnancy. Br J Haematol. 2003;120(4):574-596.

5. Portielje JE, Westendorp RG, Kluin-Nelemans HC, Brand A. Morbidity and mortality in adults with idiopathic thrombocytopenic purpura. Blood. 2001;97(9):2549-2554.

6. Cines DB, Bussel JB. How I treat idiopathic thrombocytopenic purpura (ITP). Blood. 2005;106(7):2244-2251.

7. Nørgaard M, Jensen AØ, Engebjerg MC, et al. Long-term clinical outcomes of patients with primary chronic immune thrombocytopenia: a Danish population-based cohort study. Blood. 2011;117(13): 3514-3520.

8. Danese MD, Lindquist K, Gleeson M, Deuson R, Mikhael J. Cost and mortality associated with hospitalizations in patients with immune thrombocytopenic purpura. Am J Hematol. 2009;84(10):631-635.

9. Bureau of Labor Statistics, United States Department of Labor. Consumer Price Index. Available from: http://data.bls.gov/cgi-bin/ surveymost?cu. Accessed November 30, 2015. 
10. Frederiksen $\mathrm{H}, \mathrm{Schmidt} \mathrm{K}$. The incidence of idiopathic thrombocytopenic purpura in adults increases with age. Blood. 1999;94(3):909-913.

11. Torbey E, Yacoub H, McCord D, Lafferty J. Two cases and review of the literature: primary percutaneous angiography and antiplatelet management in patients with immune thrombocytopenic purpura. ISRN Hematol. 2013;2013:174659.

12. Blanchette V, Freedman J, Garvey B. Management of chronic immune thrombocytopenic purpura in children and adults. Semin Hematol. 1998;35(1 Suppl 1):36-51.

13. Provan D, Newland A. Fifty years of idiopathic thrombocytopenic purpura (ITP): management of refractory ITP in adults. Br J Haematol. 2002;118(4):933-944.
14. Neunert CE. Current management of immune thrombocytopenia. Hematology Am Soc Hematol Educ Program. 2013;2013:276-282.

15. Ghanima W, Godeau B, Cines DB, Bussel JB. How I treat immune thrombocytopenia: the choice between splenectomy or a medical therapy as a second-line treatment. Blood. 2012;120(5):960-969.

16. Pfuntner A, Wier LM, Steiner C. Costs for Hospital Stays in the United States, 2010. Statistical Brief\#146. Rockville, MD: Agency for Healthcare Research and Quality; 2013. Available from http://www.hcup-us. ahrq.gov/reports/statbriefs/sb146.pdf. Accessed November 30, 2015.

17. Gonzalez-Porras JR, Escalante F, Pardal E, et al. Safety and efficacy of splenectomy in over 65-yrs-old patients with immune thrombocytopenia. Eur J Haematol. 2013;91(3):236-241.
Vascular Health and Risk Management

\section{Publish your work in this journal}

Vascular Health and Risk Management is an international, peerreviewed journal of therapeutics and risk management, focusing on concise rapid reporting of clinical studies on the processes involved in the maintenance of vascular health; the monitoring, prevention and treatment of vascular disease and its sequelae; and the involvement of

\section{Dovepress}

metabolic disorders, particularly diabetes. This journal is indexed on PubMed Central and MedLine. The manuscript management system is completely online and includes a very quick and fair peer-review system, which is all easy to use. Visit http://www.dovepress.com/ testimonials.php to read real quotes from published authors. 